\title{
Humboldt e a formação do modelo de universidade e pesquisa alemã ${ }^{*}$
}

\author{
Humboldt and the creation of the German research university model
}

\author{
Ricardo Ribeiro Terra \\ ricardoterrausp@gmail.com \\ (Universidade de São Paulo - Cebrap, São Paulo, Brasil)
}

\begin{abstract}
Resumo: Há uma grande disputa sobre o sentido da concepção humboldtiana de universidade. Nas constantes crises e transformações das universidades, a concepção humboldtiana é retomada e usada como argumento, frequentemente, por mais de um dos lados do conflito. Neste texto pretende-se: em primeiro lugar, examinar as necessidades culturais e políticas para a fundação de uma universidade em Berlim; em segundo lugar, indicar como Wilhelm von Humboldt planejou a transformação, de maneira articulada, de todo o sistema de ensino e pesquisa da Prússia; e, finalmente, considerar como, na efetivação do projeto, formou-se a universidade de pesquisa alemã que leva em conta também a tecnologia.
\end{abstract}

Palavras-chave: Wilhelm von Humboldt; indissolubilidade de pesquisa e ensino; universidade de pesquisa; tecnologia.

\begin{abstract}
The precise conception of a Humboldtian university is still a matter in dispute. In the constant crisis and transformations underwent by these institutions, the Humboldtian conception is frequently mentioned as an argument by opposed parts. In this paper, I will take up the following lines of argumentation: (1) an examination of the cultural and political necessities on the background of the creation of a university in Berlin; (2) a demonstration of how Wilhelm von Humboldt planned the coordinated reform of the entire Prussian teaching and research network; (3) explain how, during this process, the new research university that takes technology into account was created.
\end{abstract}

Keywords: Wilhelm von Humboldt; inseparability of research and teaching; research university; technology

DOI: http://dx.doi.org/10.11606/issn.2318-9800.v24i1p133-150

A referência a Humboldt e à universidade de pesquisa é constante nas reflexões sobre a universidade. A fundação da Universidade de São Paulo em torno da Faculdade de Filosofia, Ciências e Letras é tida como sendo de inspiração humboldtiana; a fundação da Universidade de Campinas também foi pensada como retomando o espírito humboldtiano, basta ver o livro de Fausto Castilho $O$ conceito de universidade no projeto da UNICAMP (Castilho, 2008). Além de trazer uma extensa entrevista com

\footnotetext{
* Agradecimentos: a Marcos Nobre pela leitura cuidadosa do texto, a João Geraldo Martins da Cunha por preciosas indicações bibliográficas. Agradecimento especial a Bianca Tavolari por traduzir os textos alemães citados. As referências ao texto de Humboldt "Sobre a organização interna e externa das instituições científicas superiores em Berlim" seguem também a tradução de Bianca Tavolari, que será publicada posteriormente. A referência é feita ao parágrafo e não à página, facilitando a comparação com o original e com outras traduções.
} 
Fausto Castilho, o livro reproduz, em alemão e em português, o texto fundamental de Humboldt relativo à universidade.

$\mathrm{Na}$ eterna busca por mais recursos, ou quando surge alguma crise na universidade, a concepção de universidade humboldtiana é retomada e usada como argumento, frequentemente por mais de um lado em conflito. O que se entende por essa concepção? Ela foi reduzida a algumas palavras de ordem, como a indissociabilidade entre ensino e pesquisa, ${ }^{1}$ a liberdade de cátedra e a defesa da pesquisa básica desinteressada.

A universidade alemã sofreu grandes transformações no século XIX e tornou-se um modelo que exerceu uma forte influência em todo o mundo. 0 modelo alemão é conhecido como o modelo humboldtiano ou universidade de pesquisa. Certamente há uma enorme distância entre a concepção do próprio Humboldt e o modelo que foi se sedimentando durante o século XIX e início do XX. Além disso, nas reformas ocorridas no século $X X$ e, também, no século $X X I$, houve e continua havendo uma disputa sobre o significado do próprio legado de Humboldt com apropriações conservadoras competindo com apropriações, digamos, progressistas. Como ressalta Peter Uwe Hohendahl, muitas vezes o que se atribui a Humboldt tem pouco a ver com seus textos e com sua atuação histórica. ${ }^{2}$

Para precisar a questão, é necessário voltar a algumas circunstâncias vinculadas à fundação da Universidade de Berlim (I), examinar o papel de Wilhelm von Humboldt nesse processo (II) e, finalmente, examinar como foi efetivada a Universidade de pesquisa no estilo alemão (III). É necessário ter em vista o caráter parcial e esquemático da exposição que vem a seguir. Trata-se apenas de elaborar um quadro que poderá facilitar a comparação e a crítica das transformações e apropriações do modelo. ${ }^{3}$

\section{A necessidade de criação de uma universidade em Berlim}

A situação que levou à fundação da Universidade de Berlim é bastante significativa para compreender seu sentido. Podemos enumerar vários motivos que contribuíram para a tomada de consciência da necessidade da fundação de uma

\footnotetext{
1 No Brasil, como se fosse possível, Humboldt foi constitucionalizado: "Art. 207. As universidades gozam de autonomia didático-científica, administrativa e de gestão financeira e patrimonial, e obedecerão ao princípio de indissociabilidade entre ensino, pesquisa e extensão".

2 Ver o artigo esclarecedor de Hohendahl (2011); tradução em português por Ricardo Crissiuma (Hohendahl, 2013).

3 Os principais documentos teóricos relativos à fundação da Friedrich-Wilhelms-Universität zu Berlin foram coligidos em duas coletâneas: Anrich, 1964 e Weischedel, 1960. Há uma coletânea de textos traduzidos para o francês com uma útil "Présentation" escrita pelos organizadores do volume: Ferry, Pesron e Renaut, 1979a; ver também a coletânea americana: Menand, Reitter e Wellmon, 2017.
} 
universidade com perfil renovado em Berlim. ${ }^{4}$

É bom ressaltar que a discussão sobre a universidade ocorria já havia algum tempo. Os primeiros esforços institucionais renovadores foram a fundação da Universidade protestante de Halle, em 1694, por Frederico I, e a criação da Universidade de Göttingen em 1734. Elas levaram "a uma renovação tal que o universo acadêmico não conhecia desde a Idade Média” (Renaut, s.d., p. 1). A liberdade de ensino e pesquisa era muito maior do que nas esclerosadas universidades católicas, ou as que tinham substituído o controle da igreja pelo do Estado, e Halle foi a primeira universidade a ter aulas em alemão (cf. Boockmann, 1997, p. 17). A leitura direta da Bíblia e a diminuição do peso das autoridades medievais, com seus infindáveis comentários e disputas, favoreceram a renovação, criando um novo quadro para o desenvolvimento do raciocínio livre e da pesquisa. Entretanto, Halle terá grandes problemas com a disputa entre os pietistas e o movimento do esclarecimento. Isso levou à expulsão de Christian Wolff de Halle em 1723, significando um golpe na liderança da universidade, mesmo com a volta de Wollf com a subida ao trono de Frederico II, em 1740 (cf. McClelland, 2008, p. 35).

A Universidade de Göttingen foi fundada em 1734 por Gerlach Adolph von Münchhausen (1688-1770) (cf. Boockmann, 1997, p. 20), que havia estudado em Halle e queria no eleitorado de Hannover uma Universidade de excelente nível, com maior liberdade de ensino e pesquisa. A independência em relação à igreja e a influência inglesa ampliam o espírito liberal da instituição. Münchhausen procurou atrair professores relevantes para garantir a excelência, entre eles, por exemplo, Johan Friedrich Blumenbach. Preocupou-se também com as condições materiais e institucionais, com a formação de uma boa biblioteca e fundou a Sociedade de Ciência de Göttingen (1742) (cf. McClelland, 2008, pp. 34 ss). A nova universidade possibilitou uma renovação no ensino e na pesquisa com resultados excepcionais nos âmbitos da filologia e dos estudos históricos.

A grande inovação foi a difusão do seminário ao lado das aulas:

Cada método de ensino tem sua própria função pedagógica particular. A palestra [lecture] era o veículo para transmitir, da maneira mais eficiente possível, os elementos mais importantes e incontroversos do tema em discussão, para um público estudantil relativamente ignorante. 0 seminário, ao contrário, era o meio pelo qual o professor apresentava sua própria contribuição para o desenvolvimento de sua disciplina diante de um círculo de acólitos críticos, mas também admiradores adequados. A inovação de Göttingen claramente mostrou o caminho para as novas universidades orientadas para pesquisa do século XIX (Brockliss, 1996, p. 568).

Mas mesmo essa transformação teve precursores nas faculdades de medicina, onde professores organizavam o estudo e a pesquisa em pequenos grupos para estudantes mais avançados. Em Pádua, por exemplo, esses encontros constituíam importante

4 Ver Schaffstein, 1952, p. 218; Ferry, Pesron e Renaut, 1979a; Scott, 2006, p.20. 
parte do ensino (idem, ibidem).

Vários intelectuais e filósofos continuam a refletir sobre as universidades de língua alemã. Kant, por exemplo, reagindo à censura e ao obscurantismo do curto reinado de Frederico Guilherme II, tratou diretamente da censura e da relação da universidade com o Estado em 0 Conflito das Faculdades, publicado em 1798, obra na qual distinguiu as faculdades superiores: teologia, medicina e direito, da faculdade inferior, a filosofia (Kant, Der Streit der Fakultäten. AK. VII, p.28; 1993, p. 32). Para Kant, os cursos de teologia, medicina e direito podiam, sem perder suas características básicas, sofrer algum controle do Estado, pois eram vinculados diretamente à prática. A faculdade de filosofia, por sua vez, perderia os elementos básicos de sua missão se fosse sujeita ao controle externo ou à censura. A liberdade de ensino e pesquisa na filosofia e nas ciências seria absolutamente indispensável e a faculdade de filosofia deveria poder examinar criticamente todas as disciplinas, mesmo aquelas das faculdades superiores. A faculdade de filosofia, com seus dois departamentos, cobria o âmbito das ciências e das humanidades. O departamento dedicado ao conhecimento histórico compreendia a história, a geografia, o conhecimento das línguas e a parte empírica da ciência natural. 0 outro departamento se dedicava aos conhecimentos racionais puros: matemática, filosofia, metafísica da natureza e metafísica dos costumes.

Kant estava preocupado não apenas com a censura, mas também com a possibilidade de a universidade, ou melhor, a faculdade de filosofia, fazer o que chamaríamos hoje, na linguagem da Teoria Crítica, de diagnóstico de época ou, na linguagem de Foucault, de ontologia do presente, ontologia de nós mesmos. A parte de seu livro 0 Conflito das Faculdades dedicada ao conflito da faculdade de direito com a faculdade de filosofia é justamente uma maneira de pensar o acontecimento fundamental da época: a Revolução Francesa (Foucault, 1994, pp. 682 e ss). Kant ressalta o caráter crítico e investigativo da Faculdade de Filosofia em relação às "faculdades superiores" que tinham, em certa medida, um caráter utilitário.

Não apenas Kant estava preocupado com a Universidade e as transformações de seu tempo. No fim do século XVIII e início do XIX, “intelectuais da Prússia e aristocratas do Esclarecimento [Aufklärung] levaram adiante a ideia de uma nova e vibrante universidade em reação à estagnação acadêmica percebida nas universidades existentes na Alemanha" (Scott, 2006, p.20). O sistema de ensino com aulas ditadas e com programas e manuais controlados pelo Estado era então francamente criticado e a pressão por uma mudança radical era amplamente sentida. ${ }^{5}$ Por outro lado, a Revolução Francesa amplia a crítica às velhas universidades, levando a mudanças no

5 Schaffstein insiste na monotonia provocada pelos métodos antiquados "que em grande parte se limitavam ao mero ditado de um manual, permanecendo voltados a si mesmos, sem serem internamente apreendidos pela ciência" (Schaffstein, 1952, p. 217). 
ensino universitário e na formação profissional. As guerras na Europa também trazem dificuldades econômicas para a manutenção das instituições de ensino. No âmbito dos estados de língua alemã, as universidades sofriam a concorrência das Academias de Ciências e dos cursos especiais que formavam profissionais como o Collegium Medico-Chirurgicum (1724 - Berlim), a Bergakademie (1776 - Freiberg), Akademie der Kunst (Berlim - 1796), ou a Bauakademie (1799 - Berlim):

Um indício seguro para isto é, por exemplo, o fato de que, entre 1792 e 1818, o número de universidades no âmbito de língua alemã foi reduzido ao meio. 22 universidades fecharam suas portas, dentre elas as universidades de Estrasburgo, Colônia, Bonn, Ingolstadt, Fulda, Bamberg, Altdorf, Salzburgo, Frankfurt/Oder, Erfurt, Wittenberg e Münster (Mittelstrass, 1994, p. 81).

O conflito da busca desinteressada da verdade com o ensino visando a utilidade tornava-se mais grave com a baixa qualidade do ensino universitário.

Houve um longo processo na tentativa de reverter essa situação. Podemos acompanhar Alain Renaut quando afirma que:

o Conflito das Faculdades prefigurava o que iria ser realizado, uma dezena de anos mais tarde, em seguida ao debate berlinense - notadamente esse recentramento da instituição em torno de uma Faculdade de Filosofia percebida como encarnando da melhor forma a exigência universitária de uma relação ao saber subtraída aos únicos imperativos da utilidade. Quanto a esse recentramento: Schelling ou Fichte tentaram trazer outras justificações, mais especulativas que na obra de 1798, isso não enfraquece em nada a continuidade que, nesse registro, passa por Kant e remonta sem dúvida até às opções que foram tomadas sob essa relação pelas Universidades reformadas de Göttingen ou de Halle (Renaut, s.d., p.18). ${ }^{6}$

Houve um longo processo de crítica da situação desoladora das universidades alemãs, mas também iniciativas para transformar esse quadro. 0 longo processo de crítica e esforços institucionais vai da fundação das universidades de Göttingen e Halle, passando pela crítica kantiana até Fichte, Schleiermacher e Humboldt.

Nesse contexto vale a pena seguir a formação dos irmãos Humboldt, ${ }^{7}$ Wilhelm e Alexander, que tiveram uma educação privilegiada em casa com bons professores particulares. Entretanto, a experiência universitária será marcante para a formação da opinião deles a respeito do que havia de esclerosado e de inovador no ensino superior. Na Prússia, eles poderiam ter ido para Halle ou Königsberg, mas o tutor deles na época preferiu que eles fossem para a Universidade de Frankfurt an der Oder, apesar de ela não ter a qualidade da Universidade de Halle. A escolha foi motivada pela presença de um antigo tutor dos irmãos, que havia se transformado em professor da universidade e, assim, poderia continuar a orientá-los.

\footnotetext{
6 Renaut se refere a Mittelstrass quando este ressalta que os seminários filológicos seriam a Universidade propriamente dita; seguindo Schleiermacher, as outras faculdades seriam escolas especiais (cf. Mittelstrass, 1994, p. 81).
}

7 Ver a respeito do que se segue: Geier, 2016, pp. 62 e ss. e Quilien, 2015, pp. 67 e ss. 
Wilhelm frequenta a Universidade de Frankfurt an der Oder a partir de setembro de 1787; em abril de 1788, sai de Frankfurt e vai para a Universidade de Göttingen, onde fica até julho de 1789. Começa então uma longa viagem, ficando de 3 a 27 de agosto em Paris, seguindo depois para o sul da Alemanha e para a Suíça. A experiência da diferença entre as duas Universidades servirá para formar o diagnóstico de Wilhelm sobre as universidades de sua época.

É importante ressaltar que, na época, para um prussiano estudar, mesmo no âmbito do mundo alemão, não era algo simples:

É verdade que é proibido ao súdito prussiano estudar em universidades estrangeiras. Mas o edito real prussiano de 1749 não conseguiu impedir Wilhelm von Humboldt de se matricular na Georgia-Augusta em Göttingen em 23 de abril de 1788, que, na confusão que reinava à época diante da divisão da Alemanha em inúmeras pequenas cidades-estados, pertencia ao eleitorado de Hannover, em estreita ligação com a Inglaterra (Geier, 2016, p. 66).

Como vimos, a independência em relação à igreja e a influência positiva inglesa possibilitaram um espírito, digamos, mais liberal na instituição. A filologia e a história eram pontos de destaque; entretanto, o ponto fraco era a filosofia com J. G. Feder, crítico menor de Kant. ${ }^{8}$ Humboldt aproveitou muito os estudos de filologia e história da Grécia antiga, além de seguir os cursos de Blumenbach e os cursos de Lichtenberg sobre a luz, eletricidade e magnetismo. Como se pode constatar, seus interesses intelectuais eram muito amplos. A experiência de Wilhelm em Göttingen em relação aos cursos e seminários de filologia, história e ciências foi marcante de tal forma que podemos afirmar, seguindo, por exemplo Jean Quilien, que ele tomou a Universidade de Göttingen como um primeiro modelo para a universidade a ser fundada em Berlim. Por outro lado, também teve a experiência da velha Universidade alemã, durante o período em Frankfurt/ Oder. Frankfurt estava entre as 22 universidades alemãs que fecharam suas portas no fim do século XVIII e no início do século XIX, como vimos acima. A Universidade de Frankfurt/Oder foi fundada em 1506, foi fechada em 1811, só sendo refundada em 1991.

Além da situação precária de algumas universidades prussianas, outro motivo para a fundação de uma Universidade em Berlim foi o tratado de Paz de Tilsitt (julho de 1807) celebrado pela Prússia com a França napoleônica, pois, com esse tratado, a Prússia perdia o ducado de Magdeburg e, assim, sua mais importante universidade

8 Devido à fraqueza do ensino de filosofia em Göttingen, no plano filosófico, a evolução intelectual de Humboldt "se efetua, nos anos decisivos 1788 e 1789, fora da universidade, através de sua primeira leitura de Kant, durante o verão de 1788, e seus encontros com Forster e Jacobi em outubro e novembro do mesmo ano" (Quilien, 2015, p. 69). 
em Halle. Os professores da Universidade de Halle solicitam então sua mudança para uma cidade em uma região não ocupada pelos estrangeiros, e Friedrich Wilhelm III pronuncia a célebre frase: "O Estado tem de substituir por forças espirituais o que perdeu em forças físicas” (Schaffstein, 1952, p. 219), ${ }^{9}$ e já em setembro de 1807 encarrega o ministro <Kabinettsrat> Beyme de fundar uma universidade em Berlim. O caráter nacional alemão está, pois, fortemente presente desde o início nos planos da fundação de uma universidade renovada na Prússia.

Beyme escreve a vários intelectuais consultando-os sobre o espírito que deveria presidir a nova universidade. Fichte faz uma proposta com o texto "Plano dedutivo de uma instituição superior de ensino a ser fundada em Berlim" (1807) e Schleiermacher responde com outra proposta, "Pensamentos ocasionais sobre universidades no sentido alemão” (1808) (Fichte, 1964; Schleiermacher, 1964).

Após ouvir outros intelectuais além de Fichte e Schleiermacher, Beyne confia a organização da nova universidade a Humboldt no fim de 1808. Das propostas apresentadas, a de Schleiermacher é a que prevalece. Na célebre obra Fichte et son temps, ${ }^{10}$ Xavier Léon opõe a concepção, digamos, mais liberal em relação à liberdade dos professores e dos alunos de Schleiermacher à posição vista por este como um “autoritarismo tirânico" de Fichte (Léon, 1927, pp.148 e 145). Humboldt teria sido mais influenciado pela perspectiva liberal, ou seja, pela ideia da autonomia de alunos e professores. Além disso, é importante notar que era claro para todos que a dependência da universidade em relação ao Estado deveria ser limitada ao mínimo. Nesse sentido, o Estado deveria fornecer apoio financeiro à universidade ao mesmo tempo em que aceitaria a independência de pesquisa e ensino em relação aos fins práticos imediatos; em relação às disciplinas, assumia-se uma atitude liberal, recusando sua unificação sob a tutela de uma filosofia muito abstrata e defendendo, pelo contrário, uma compreensão de filosofia como reflexão sobre as ciências positivas. Já a posição de Fichte era muito mais interventora e controladora (cf. Leon, 1927, p.145). O mais interessante - e, de resto, expressão da pluralidade na nova universidade - é que Fichte se tornará diretor da Faculdade de Filosofia e Schleiermacher, da Faculdade de Teologia. O jurista Theodor Schmalz (1810/11), primeiro reitor da Universidade, foi nomeado pelo rei, o primeiro eleito foi Fichte (1811/12) e, o segundo, Friedrich Karl von Savigny (1812/13) (Tenorth, 2012, p. 655).

\section{Humboldt Diretor da Seção de Culto e Educação do Ministério do Interior}

Humboldt tomou posse como Diretor da Seção de Culto e Educação do Ministério

9 „Der Staat muss durch geistige Kräfte ersetzen, was er an physischen verloren hat“

10 Ver também "Présentation" (Ferry, Pesron e Renaut, 1979a, pp.17 e seguintes); para uma posição diferente, insistindo mais na presença de Fichte na posição de Humboldt, ver o texto citado de Schaffstein (1952). 
do Interior no dia 28 de fevereiro de 1809, onde ficou 16 meses. Seu pedido de demissão foi aceito no dia 14 de junho 1810 (Geier, 2016, p. 262), portanto antes da abertura da Universidade de Berlim, que aconteceu no dia 10 de outubro. ${ }^{11}$ Humboldt assumiu então um posto em Viena (Cf. Werke V, 555).

É importante ressaltar que, além da religião, a seção cuidava de todo o sistema educacional, o que permitia e exigia que Humboldt pensasse não apenas a universidade, mas também o ensino e todas as instituições científicas e culturais, como as academias e museus. Nesse quadro, a visão orgânica da formação dos indivíduos e da nação alemã poderia ser contemplada em sua amplitude. Humboldt começa uma extensa rearticulação de todo o sistema de ensino e o ápice foi a criação da Universidade de Berlim.

Mas é bom lembrar que a situação histórica do ensino era complexa com a decadência e irrelevância de boa parte das universidades europeias e com a profunda reformulação que aconteceu em decorrência da Revolução Francesa. Havia ainda outro complicador, a relação das universidades com as academias. Não se pode esquecer de mencionar que boa parte da revolução científica moderna não se deu nas universidades.

A polêmica academia versus universidade, pesquisa versus ensino, é rica e antiga e, em certo sentido, continua até hoje. ${ }^{12}$ Gingras contrapõe, de um lado, Condorcet e Newman e, de outro, Humboldt.

Preocupado com a possibilidade de transformar as sociedades científicas e instituições de ensino, Condorcet escreve em 1791: “o talento de instruir não é o mesmo daquele que contribui ao progresso das ciências: o primeiro exige sobretudo clareza e método; o segundo, força e sagacidade" (Condorcet, 2017, p. 167). São funções distintas, mas é claro que a ciência produzida nas sociedades científicas deve influenciar o ensino. Mais de quarenta anos depois da fundação da universidade de Berlim, o Cardeal Newman continua pensando que, combinadas,

a natureza do caso e a história da filosofia nos recomendam essa divisão do trabalho intelectual entre academias e universidades. Fazer descobertas e ensinar são funções distintas; são também dons distintos e não são comumente encontradas na mesma pessoa. Aquele que passa seu dia distribuindo seu conhecimento a todos os interessados dificilmente terá tempo livre ou energia para adquirir conhecimentos novos. O senso comum da humanidade associou a busca pela verdade com o isolamento (seclusion) e com o silêncio (Newman, 1996, p. 5).

Ao contrário de Condorcet e Newman, um dos pontos centrais da perspectiva humboldtiana é a indissociabilidade de ensino e pesquisa na universidade. Desta

11 Em sua carta de demissão de 29 de abril de 1810, no último parágrafo, escreve: "Recolho-me de bom grado na solidão (Einsamkeit)" (Werke, IV, 254). O conceito de Einsamkeit surge em diversos contextos na obra de Humboldt, caracterizando uma importante necessidade do intelectual.

12 Devo muito no que segue ao artigo de Gingras (2003). 
forma, para fundar a nova universidade, Humboldt terá que repensar as funções das academias, museus e universidade ${ }^{13}$ e, como Diretor da Seção de Culto e Ensino, tinha que articular às universidades todo o sistema de ensino.

Há, entretanto, grandes dificuldades para se reconstruir o pensamento de Humboldt a respeito do ensino em geral e da universidade em particular. Os textos específicos sobre esses temas a que temos acesso são textos administrativos não preparados para serem publicados. São relatórios a respeito das atividades da Seção de Culto e Ensino, um texto inacabado, digamos, mais teórico, "Sobre a organização interna e externa das instituições científicas superiores em Berlim”, e a correspondência pessoal. 0 texto mais discutido e traduzido é o texto mais filosófico, onde são elaborados os princípios gerais e que levou a um grande debate. Esse texto é o que geralmente consta nas coletâneas traduzidas em diversas línguas. ${ }^{14}$ Mas mesmo esse texto é um memorando escrito em função da administração política (Volker, 2007, p. 56).

Em suma, é necessário levar em conta os documentos administrativos escritos por Humboldt durante sua chefia da Seção tanto pela argumentação defendendo seu projeto como também para mostrar as dificuldades e a situação da Prússia naquele período.

Muitos documentos são importantes para se ter uma ideia da reforma do sistema de ensino. Vamos nos referir apenas a um deles, „Der Königsberger und der Litauische Schulplan“ (12 de maio 1809). Em relação à fundação da Universidade de Berlim, também muitos textos são importantes. Vamos nos referir apenas aos seguintes: "Antrag auf Errichtung der Universität Berlin“ (12 de maio de 1809), „Antrag auf Errichtung der Universität Berlin“ (24 de julho de 1809) e o texto clássico sobre a "Organização". 15

Humboldt planejava remodelar todo o sistema de ensino prussiano. É importante levar isso em conta e não ficar apenas olhando para a fundação da Universidade de Berlim. O bom funcionamento da universidade inclusive dependia de ter alunos bem formados no curso secundário. Para Humboldt, a Bildung do povo/nação alemão é

13 A questão das funções da universidade, das academias (atualmente dos institutos de pesquisa) tem sido retomada com força, principalmente com o advento da universidade de massa. Na Alemanha há um complexo sistema de Universidades, Universidades Técnicas, Institutos Max Planck, Institutos Fraunhofer, Exzellenz Clusters.

14 Uma exceção é a coletânea, já citada, editada por Louis Menand, Paul Reitter \& Chad Wellmon, onde foi reproduzido, além do texto costumeiro de Humboldt, partes do „Antrag auf Errichtung der Universität Berlin“, escrito em maio e enviado em julho 1809. Cf. Menand, Reitter e Wellmon, 2017, pp. 116 e seguintes. Sobre a escrita e envio do texto, ver: Humboldt Werke V, p. 517.

15 Muitos outros textos são da maior importância, para citar apenas alguns: „Über die königliche Bibliothek zu Berlin“, „Über die Organisation des Medizinalwesens“, „Über finanzielle Dotierung der wissenschaftlichen Institute“, „Über den Unterricht im Zeichen“, „Über Aufhebung des Verbots, fremde Universität zu besuchen“, „Zur Einrichtung eines Museums in Berlin“. Bianca Tavolari e eu estamos planejando elaborar uma coletânea comentada desses textos. 
um processo que envolve todo o aparato cultural e político e deveria ser liderado pela Prússia.

Como os textos administrativos não foram traduzidos para o português e geralmente não têm sido levados em conta nos estudos sobre a universidade, vale a pena fazer longas citações, inclusive para ajudar na análise do texto fundamental "Sobre a organização interna e externa das instituições científicas superiores em Berlim".

Em primeiro lugar, reproduzimos um importante trecho de „Der Königsberger und der Litauische Schulplan“. Na passagem referida, encontra-se sintetizada a concepção geral de Humboldt expressa com clareza a respeito do sistema de ensino:

Eu só posso reconhecer como estágios naturais: ${ }^{16}$

a educação elementar

a educação escolar

a educação universitária

A educação elementar abarca meramente a designação das ideias de acordo com todos os tipos e sua primeira classificação originária. Ela também pode, sem qualquer prejuízo, incorporar mais ou menos objetos na matéria a esta forma no conhecimento da natureza e da Terra. É ela que torna possível aprender coisas propriamente ditas e seguir um professor.

Então a educação escolar introduz o aluno à matemática, a conhecimentos linguísticos e de história até o ponto em que seria inútil vinculá-lo a um professor e à própria aula. Ela torna o aluno cada vez mais livre do professor, mas ensina a ele tudo o que um professor pode ensinar.

A universidade está reservada para o que a pessoa só pode encontrar por ela própria e nela própria: o acesso [Einsicht] à ciência pura. Para esse ato próprio [SelbstActus] em direção ao entendimento mais próprio, é necessário liberdade e uma solidão [Einsamkeit] útil - e é a partir desses dois pontos que, ao mesmo tempo, flui toda a organização externa das universidades. Seguir cursos é apenas algo lateral. 0 essencial é estar em comunidade próxima com pessoas da mesma opinião e com os pares, e a consciência de que, no mesmo lugar, já existe um número de pessoas que já completaram sua formação [vollendet Gebildeter] que se dedicam apenas à elevação e à difusão da ciência (Humboldt, IV, 191). ${ }^{17}$

16 Esta primeira frase é da parte do texto referente à Lituânia; na parte referente a Königsberg encontra-se a seguinte versão: "Tomado filosoficamente há apenas três estágios no ensino" (Werke IV, 169).

17 Walter Rüegg comentando o último parágrafo, escreveu: “Em contraste com as liberdades do estudante da Universidade medieval e da primeira modernidade, a liberdade pessoal, que 
Em segundo lugar, vale a pena reproduzir uma passagem que sintetiza como a função do professor muda completamente dependendo do nível de ensino. Convém ressaltar a diferença da função no estudo elementar e no ensino médio:

Assim, se é a educação elementar que torna o professor possível pela primeira vez, então ele se torna dispensável por meio da educação escolar. Por isso, o professor universitário também não é mais um professor, o aluno da universidade também não é mais um aprendiz, mas pesquisa por si próprio e o professor orienta sua pesquisa e lhe dá apoio (Humboldt, IV, 170).

O caminho é o da via para a autonomia.

Além de dividir o sistema educacional em três estágios e insistir na diferença e na articulação de mestres e docentes em cada um deles, Humboldt propõe mudanças importantes em todos os tipos de escolas. Escolas mais voltadas para as profissões e escolas voltadas para a erudição. Insistência no ensino de francês e inglês, ao lado do latim e do grego, em algumas, estudo de tecnologia, estatística, experimentos químicos e fórmulas de cálculo, em outras.

Humboldt leva a sério a formação cultural da nação, mas também considera o necessário preparo para as profissões, daí o cuidado para que existam muitas escolas especiais já que:

nenhum ofício importante da vida civil dispensa uma escola como estas. O que é ensinado de tecnologia nas escolas burguesas poderia muito bem ser vinculado às escolas de arte, em que muitos artesãos já têm aulas hoje. Além disso, como acontece em Berlim, eles poderiam ouvir palestras [Vorlesungen] técnicas e sobre química e, como muitos vagueiam e viajam, não haveria problema se estas escolas estivessem apenas em alguns lugares da monarquia. Hoje já existem escolas de agricultura, comércio e para formar pilotos. Bem como instituições para médicos não formados cientificamente e assim por diante (Humboldt, IV, 174/175).

É sempre importante ressaltar que este projeto de transformação do ensino não leva apenas à pesquisa desinteressada da universidade, ou melhor, ela só é possível porque existe um complexo sistema de ensino. Voltarei ao tema adiante.

Passemos à fundação da Universidade de Berlim. Dois textos são centrais para a compreensão da posição de Humboldt. O primeiro tem duas versões: „Antrag auf Errichtung der Universität Berlin“, de 12 de maio de 1809, cuja segunda versão data de 24 julho de 1809, mantendo o título. Já o segundo texto, que ficou incompleto, tem o título "Sobre a organização interna e externa das instituições científicas superiores em Berlim".

Vale a pena mais uma longa citação da segunda versão do Antrag, onde Humboldt pretende articular o ensino e a pesquisa, relacionando a universidade e as

oferece aos estudantes uma educação acadêmica de acordo com o modelo da Universidade de Berlim, refere-se ao estudo como sendo o núcleo de suas atividades, e o atribui à sua própria responsabilidade" (Rüegg, 2004, p. 21). 
academias, e também demonstrar que a cidade de Berlim seria o lugar ideal para a nova instituição:

A primeira ideia de uma instituição de ensino superior e geral em Berlim se originou indiscutivelmente da observação de que, além das duas academias, de fato já existem hoje em Berlim uma grande biblioteca, mirantes, um jardim botânico e muitas coleções, uma faculdade de medicina completa. Sentia-se que qualquer separação de faculdades seria ruinosa para a formação científica genuína, que coleções e institutos, como os citados acima, só se tornam realmente úteis quando estão vinculados à educação científica completa e que, por fim, para adicionar a esses fragmentos aquilo que pertence a uma instituição geral, era necessário dar apenas mais um passo à frente.

A Seção ${ }^{18}$ também permanece fiel a este ponto de vista.

Seu desejo consiste em conectar

a Academia de Ciências,

a Academia das Artes,

os institutos científicos,

a saber, os institutos clínicos, anatômicos e médicos, na medida em que são de natureza puramente científica, a biblioteca, o observatório, o jardim botânico e as coleções de história natural e de artes e a própria instituição geral de ensino em Um todo orgânico, de tal forma que cada parte, na medida em que ela adquire uma certa independência, ainda assim coopera com as demais para uma finalidade geral.

Desta maneira de olhar a coisa, resulta uma determinação de lugar, a saber: que uma instituição como esta só poderia ter lugar em Berlim (Humboldt, „Antrag auf der Errichtung der Universität Berlin - Juli 1809“, pp.114/115).

Por outro lado, Humboldt estava plenamente consciente de que a autonomia financeira era fundamental para a universidade. Daí sua proposta, que infelizmente não foi aceita:

Assim, seria o mais adequado possível à finalidade, se a universidade e os institutos a ela vinculados recebessem seu rendimento anual por meio da concessão de bens do domínio. Não podemos negar as desvantagens decorrentes da doação de instituições públicas, geralmente a má administração e no que diz respeito à mudança nos preços decorrente na própria mudança do quanti, mas elas podem ser atenuadas por diversos meios. Para que o Estado não perca seus domínios, a mesma quantia de bens espirituais católicos poderia ser secularizada na Silésia e na Prússia Ocidental, tornando-se domínio público (idem, pp.117-118).

O texto seminal de Humboldt "Sobre a organização interna e externa das instituições científicas superiores em Berlim” tornou-se uma espécie de manifesto da universidade moderna, sendo mais citado que lido e estudado. É um artigo incompleto

18 Seção de Culto e Ensino do Ministério do Interior. 
e só foi publicado muito depois de escrito. ${ }^{19}$ É um texto difícil, pois está mergulhado nas discussões da época em relação à filosofia, à ciência, à arte e à política. Vamos nomear algumas questões, mas desenvolver apenas algumas que tiveram uma maior influência na história da universidade moderna. Como disse acima me referindo a Hohendahl, a herança humboldtiana é disputada por posições filosóficas e políticas muito diferentes. ${ }^{20}$

Encontramos o quadro geral da missão nacional da universidade já na abertura do texto:

O conceito de instituições superiores científicas, como a culminação de tudo o que toca diretamente à cultura moral da nação, baseia-se no fato de que elas são destinadas a trabalhar a ciência no sentido mais amplo e profundo do termo e entregar-se ao uso de sua matéria entendida não como algo preparado de forma intencional, mas como a matéria, por si mesma conforme a um fim [zweckmäßig], da formação [Bildung] espiritual e moral (Humboldt, „Über die innere und äußere Organisation der Höheren Wissenschaftlichen Anstalten in Berlin“, p. 255, tradução Bianca Tavolari \# 1).

Para Humboldt, a ciência é central no quadro da formação cultural e moral da nação alemã. Os estabelecimentos científicos superiores devem realizar a ligação da própria ciência com a formação dos pesquisadores independentes e também garantir a passagem da formação escolar para a formação da independência intelectual. Diferentemente da escola, que ensina conhecimentos já estabelecidos, a universidade assume a ciência como uma tarefa infinita, nunca acabada. A relação professor-aluno é diferente na escola e na universidade: nesta, o professor não está lá para o aluno, "ambos estão lá ou existem para a ciência [Beide sind für die Wissenschaft da]" (idem, p. 256, idem \# 4).

No entanto, uma vez que essas instituições somente podem atingir seu fim se se confrontarem, tanto quanto possível, à ideia pura da ciência, a solidão e liberdade são os princípios que prevalecem em seu círculo (idem, p. 254, idem \#3).

A expressão "Einsamkeit und Freiheit" tornou-se um lema do novo modelo de universidade, a universidade de pesquisa, onde há a indissociabilidade real de ensino e pesquisa. A liberdade de ensino é acompanhada da liberdade de aprender, há uma comunidade formada em torno do cultivo da ciência. Em Berlim, as ciências faziam parte da faculdade de filosofia e lá se criou a forma moderna de doutorado nas várias ciências (Levere, 2001, p. 118).

\section{Efetivação da Universidade de estilo alemão}

19 A primeira parte foi publicada apenas em 1896 e o texto inteiro em 1900, ver Humboldt, Werke V, p. 556.

20 Pretendo em outro artigo desenvolver uma análise detida do texto; esse primeiro ensaio serve para preparar o caminho. 
Se nos voltarmos para a realização efetiva da nova universidade e a criação do que se chamará de universidade de pesquisa de estilo alemão, não podemos nos deter apenas nos textos administrativos ou apenas nos textos mais teóricos de Humboldt. Não podemos nos esquecer que Humboldt não participou nem mesmo da abertura da Universidade, tendo assumido outro cargo em Viena. Na vida efetiva da universidade encontra-se uma presença bem maior de seu irmão Alexander von Humboldt, inclusive no reforço das ciências naturais e experimentais. ${ }^{21}$ No início da universidade surgiram várias dificuldades e levou certo tempo para que pesquisa e ensino se articulassem de fato nos diversos campos do conhecimento, bem como para a instalação de bons laboratórios. ${ }^{22}$

A formulação da universidade de pesquisa alemã não se deve apenas à Universidade de Berlin, deve-se levar em conta as precursoras como Halle e Göttingen e também a outras Universidades como a de Giesen.

A renovação das universidades no correr do século XIX levou a rearticulações e à ampliação das missões da universidade alemã. Ao lado da Bildung dos cidadãos e da nação, as várias facetas do sistema de ensino primário e secundário, as Universidades, Universidades Técnicas e institutos de pesquisa procuraram responder às exigências políticas de um lado, e, de outro, às exigências para superar, no dizer de Marx, a "miséria alemã", o descompasso entre a Alemanha dividida em atrasadas pequenas entidades políticas e as nações mais industrializadas.

Habermas chama a atenção para três elementos que exigiram transformações na Universidade: em primeiro lugar, o número cada vez maior de profissões acadêmicas; em segundo lugar, a emancipação das ciências, a dificuldade crescente de se pensar sua unidade e, desta forma, "a perda, por parte da filosofia, de seu monopólio para a interpretação da cultura em seu todo" (Habermas, 2003, p. 92). Em terceiro lugar,

a ciência avançou para uma importante força produtiva da sociedade industrial. Tendo em vista o Liebigs Institut em Gießen, o governo de Baden, já em 1850, ressaltara como exemplo o significado extraordinário da química para a agricultura (J. Klüwer). As ciências naturais perdiam sua função de constituição de mundo em benefício da produção de saber utilizável tecnicamente. As condições de trabalho da pesquisa organizada de forma institucional eram menos talhadas para funções de formação geral do que para imperativos funcionais de economia e administração (idem, ibidem).

Para entendermos a revolução que significou a nova universidade alemã, é necessária a referência a esse outro elemento fundamental ao lado do seminário de ensino, a saber, o laboratório universitário de pesquisa e ensino. Nesse contexto, é

21 Sobre a presença de Alexander von Humboldt na Universidade e o enorme sucesso de seus cursos, a partir de novembro de 1827, ver Wulf, 2016, p. 193.

22 "O equipamento dos laboratórios das ciências naturais era também precário por volta do meio do século dezenove. A conhecida crítica de Liebig ao péssimo estado dos laboratórios de química foi formulada ainda em 1840, mas talvez não fosse mais realidade na química em geral" (Tenorth, 2012, p. 240). 
enorme a relevância do trabalho de Justus Liebig, que consolidou o laboratório de pesquisa e a relação com a indústria. A influência de Liebig foi imensa na formação de uma quantidade enorme de professores pesquisadores para vários países da Europa. “De 1824 até 1852, quando Liebig deixou Gießen, havia mais de setecentos alunos matriculados em química e farmácia em seu laboratório” (Levere, 2001, p 132). Além de professores, Liebig formou farmacêuticos e também profissionais para a indústria química. Ao lado da pesquisa desinteressada, a nova universidade alemã também se abriu para a pesquisa "aplicada". Nesse sentido, uma figura importante foi August Wilhelm von Hoffman,

o discípulo mais significativo de Liebig na consolidação e extensão do modelo de laboratório de pesquisa e ensino; com seu trabalho sobre alcatrão de hulha e seus derivados, ele foi também uma figura chave no estabelecimento da indústria alemã de corantes de anilina. Ele é o exemplo perfeito da ligação entre pesquisa universitária e produção industrial (idem, p.133).

Mas Liebig vai mais longe ainda e publica textos em linguagem simples tratando de aspectos da química voltados para a agricultura e criação de animais, textos rapidamente traduzidos para o inglês.

A interação das universidades alemãs com o setor produtivo criou o modelo de universidade de pesquisa, no qual o ensino é indissociável desta última e no qual há uma abertura para a indústria e a difusão de conhecimentos diretamente para a sociedade. Esse modelo se expandiu mundialmente:

universidades americanas importaram o modelo, reformando instituições antigas e fundando novas universidades no final do século XIX com um duplo mandato em ensino e pesquisa. A primeira universidade a importar o modelo alemão de pesquisa acadêmica foi a John Hopkins University, aberta em 1876. As universidades inglesas, nas quais ensino e pesquisa eram, anteriormente, atividades distintas, seguiram o exemplo, conferindo títulos de doutor aos estudantes de pesquisa muito tardiamente; o título de Ph. D foi dado pela primeira vez na Inglaterra em 1919 (idem, p.128).

Reunindo os elementos expostos até aqui, podemos articular as missões da universidade alemã de pesquisa da seguinte forma, sem esquecer que alguns desses itens foram sendo abandonados, por exemplo, a centralidade da filosofia: ${ }^{23}$

- Inseparabilidade de ensino e pesquisa;

- Liberdade de ensino e pesquisa e também liberdade de aprender. 0 aluno pode articular sua formação levando em conta seus interesses intelectuais e não apenas profissionais;

- Criação de uma comunidade de ensino e pesquisa, a inseparabilidade de ensino e pesquisa levando à formação de uma comunidade;

- As noções de Bildung e Wissenschaft articuladas levando a uma noção de formação

23 Ver, entre outros, Scott, 2006, p.23. 
individual e também coletiva da nação e conduzindo à ideia da formação de uma elite e do solo científico, cultural e linguístico da nação alemã em busca da unificação;

- Centralidade da filosofia, das ciências e das artes na universidade, competindo no mesmo nível das antigas faculdades superiores: teologia, medicina e direito;

- Pesquisa desinteressada;

- Método de seminários;

- Estudos monográficos;

- Liderança pelas cátedras;

- Aulas em laboratórios;

- Pesquisa aplicada, relação com a indústria e difusão de conhecimentos técnicos.

\section{Considerações finais}

Humboldt enfrentou uma situação de grandes transformações culturais e amplas crises políticas, tendo que tomar importantes decisões em relação a questões disputadas e fundar novas instituições superiores visando as necessidades culturais do Estado e da sociedade. Humboldt participou da discussão sobre o fechamento das universidades esclerosadas e sobre a criação de institutos especializados, como na França, preferindo inventar uma nova forma de universidade. Tentou resolver a questão da separação do ensino na universidade e a pesquisa nas academias pregando a indissociabilidade de ensino e pesquisa. Defendeu a autonomia tanto financeira como intelectual. A liberdade de ensino e de aprendizado constituíram a marca da universidade alemã. Preparou campo para se enfrentar o grande desafio da conciliação das exigências internas das ciências com as exigências do Estado e da sociedade.

Guardadas as grandes diferenças históricas, nós nos encontramos agora em uma situação comparável: uma enorme crise política, lutando pela autonomia financeira, pela liberdade de ensino e pesquisa e tendo de responder a mudanças muito rápidas na maneira de se fazer ciência, vinculada com as exigências do Estado, da sociedade e, cada vez mais, da economia. A transformação da ciência na principal força produtiva coloca novos desafios para a Universidade. A ciência e a técnica são desenvolvidas, não apenas na Universidade e institutos de pesquisa, mas também nas próprias empresas e mesmo em órgãos estatais. A propriedade intelectual coloca novos desafios. Outro desafio que necessita de muita coragem para ser enfrentado é o necessário fechamento de instituições ou parte delas que funcionam mal.

Certamente querer apenas voltar a Humboldt é impossível, mas a maneira em que foi criada a universidade de pesquisa de estilo alemão, em reação a uma situação dada, pode nos inspirar na necessária invenção que teremos que realizar nas universidades em países periféricos. 


\section{Referências}

Anrich, E. (org.). (1964). Die Idee der deutschen Universität. Darmstadt: WBG.

Boockmann, H. (1997). Göttingen. Vergangenheit und Gegenwart einer europäischen Universität. Göttingen: Vandenhoeck \& Ruprecht in Göttingen.

Brockliss, L. (1996). "Curricula”. In: Rüegg, W. (org.). A History of the University in Europe. Volume II Universities in Early Modern Europe (1500-1800). Cambridge: Cambridge University Press.

Castilho, F. (2008). O conceito de universidade no projeto da UNICAMP. Campinas: Editora Unicamp.

Condorcet. (2017). Cinq mémoires sur l'instruction publique. Paris : GF - Flammarion.

Ferry, L.; Pesron, J.-F.; Renaut, A. (1979). Philosophie de L'Université. L'idéalisme allemand et la question de l'université. Paris: Payot.

. “Présentation”. (1979a). In: Philosophie de L'Université. L'idéalisme allemand et la question de l'université. Paris: Payot.

Fichte, J. G. (1964). „Deduzierter Plan einer in Berlin zu errichtenden höheren Lehranstalt“. In: Anrich, E. (org. ). Die Idee der deutschen Universität. Darmstadt: WBG.

Foucault, M. (1994). “Qu’est-ce que les Lumières?”. In: Dits et Écrits. Paris: Gallimard.

Geier, M. (2016). Die Brüder Humboldt. Eine Biographie. Reinbek: Rowohlt Taschenbuch Verlag.

Gingras, Y. (2003). Idées d'universités. Enseignement, recherche et innovation. Actes de la recherche en sciences sociales, 148, pp. 3-7.

Habermas, J. (2003). “Die Idee der Universität - Lernprozesse“. In: Zeitdiagnosen. Frankfurt: Suhrkamp [publicado antes em: Habermas, J. (1987). Eine Art Schadensabwicklung. Kleine politische Schriften VI. Frankfurt].

Hohendahl, P. U. (2011). Humboldt Revisited: Liberal Education, University Reform, and the Opposition to the Neoliberal University. New German Critique, 113, v.38(2), pp. 159-196 [tradução brasileira: (2013). Humboldt revisitado: educação liberal, reforma universitária e a oposição à universidade neoliberal. Tradução de Ricardo Crissiuma. Revista fevereiro - política, teoria, cultura, 6. Recuperado de: http: //www.revistafevereiro.com/pag.php? $r=06 \& t=04$. Acesso em: $16 \mathrm{dez}$. 2018].

Humboldt, W. von. Schriften zur Politik und zum Bildungswesen. Werke IV, WBG, 2010.

Werke, IV. „Antrag auf der Errichtung der Universität Berlin - Juli 1809“. In:

„Über die innere und äußere Organisation der Höheren Wissenschaftlichen Anstalten in Berlin“. In: Werke.

Kant, I. Der Streit der Fakultäten. Akademie Ausgabe, Band VII.

Edições 70.

(1993). O conflito das faculdades. Traduzido por Artur Morão. Lisboa:

Léon, X. (1927). Fichte et son temps. II Fichte à Berlin (1799-1813). Deuxième partie 
La lutte pour l'affranchissement national (1806-1813). Paris: Armand Colin.

Levere, T. (2001). Transforming Matter. A history of Chemistry from Alchemy to the Buckyball. Baltimore and London: The John Hopkins University Press.

McClelland, C. (2008). State, society and university in Germany 1700-1914. Cambridge: Cambridge University Press

Menand, L.; Reitter, P.; Wellmon, C. (orgs.). (2017). The Rise of Research University. A sourcebook. Chicago: University of Chicago Press.

Mittelstrass, J. (1994). Die unzeitgemäße Universität. Frankfurt: Suhrkamp.

Newman, J. H. (1996). The Idea of University. New Haven and London: Yale University Press.

Quilien, J. (2015). L'anthropologie philosophique de Wilhelm von Humboldt. Villeneuve-d'Ascq: Presses Universitaires du Septentrion.

Renaut, A. (s.d.). Le Modèle Humboldtien. Centre International de Philosophie Politique Appliqué. Paris Sorbonne Université. Recuperado de: http://cippa. paris-sorbonne.fr/?page id=1071. Acesso em: 31 mar. 2018.

Rüegg, W. (2004). “Themes”. In: Rüegg, W. (org.). A History of the University in Europe. Volume III Universities in the Nineteenth and Early Twentieth Centuries (1800-1945). Cambridge: Cambridge University Press.

Schaffstein, F. (1952). Wilhelm von Humboldt. Ein Lebensbild. Frankfurt: Vittorio Klostermann.

Schleiermacher, F. (1964). „Gelegentliche Gedanken über Universitäten im deutschen Sinn“. In: Anrich, E. (org.). Die Idee der deutschen Universität. Darmstadt: WBG.

Scott, J. C. (2006). The Mission of the University: Medieval to Postmodern Transformations. The Journal of Higher Education, 77 (1), pp. 1-39. DOI: https: // doi.org/10.1080/00221546.2006.11778917.

Tenorth, H.-E. (2012). „Studenten, Studium und Lehre“. In: Tenorth, H.-E. (Hrsg.) Geschichte der Universität Unter den Linden. 1 Gründung und Blütezeit der Universität zu Berlin 1810-1918. Berlin: Akademie Verlag.

Volker, G. (2007). „Humboldts Idee. Zur Aktualität des Programms Wilhelm von Humboldts“. In: Henningsen, B. (Hg.). Humboldts Zukunft. Das Projekt Reformuniversität. Berlin: Berliner Wissenschafts -Verlag.

Weischedel, W. (org.). (1960). Idee und Wirklichkeit einer Universität. Dokumente zur Geschichte der Friedrich-Wilhelms-Universität zu Berlin. Berlin: Walter de Gruyter.

Wulf, A. (2016). The Invention of Nature. Alexander von Humboldt new World. New York: Alfred A. Knopf.

Esta obra está licenciada com uma Licença Creative Commons Atribuição-NãoComercial-Compartilhalgual 4.0 Internacional.

https: //creativecommons.org/licenses/by-nc-sa/4.0/

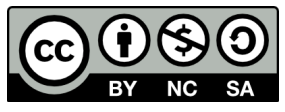

